Article

\title{
YerA41, a Yersinia ruckeri Bacteriophage: Determination of a Non-Sequencable DNA Bacteriophage Genome via RNA-Sequencing
}

\author{
Katarzyna Leskinen ${ }^{1}$, Maria I. Pajunen ${ }^{1}{ }^{\mathbb{D}}$, Miguel Vincente Gomez-Raya Vilanova ${ }^{1} \mathbb{B}$, \\ Saija Kiljunen ${ }^{1}\left(\mathbb{D}\right.$, Andrew Nelson ${ }^{2}$, Darren Smith ${ }^{2}$ and Mikael Skurnik ${ }^{1,3, *}$ \\ 1 Department of Bacteriology and Immunology, Medicum, Human Microbiome Research Program, Faculty of \\ Medicine, University of Helsinki, 00014 UH Helsinki, Finland; katarzyna.leskinen@helsinki.fi (K.L.); \\ maria.pajunen@helsinki.fi (M.I.P.); miguel.gomez-raya@helsinki.fi (M.V.G.-R.V.); \\ saija.kiljunen@helsinki.fi (S.K.) \\ 2 Applied Sciences, University of Northumbria, Newcastle upon Tyne NE1 8ST, UK; \\ andrew3.nelson@northumbria.ac.uk (A.N.); darren.smith@northumbria.ac.uk (D.S.) \\ 3 Division of Clinical Microbiology, Helsinki University Hospital, HUSLAB, 00290 Helsinki, Finland \\ * Correspondence: mikael.skurnik@helsinki.fi; Tel.: +358-2941-26464
}

Received: 17 January 2020; Accepted: 4 June 2020; Published: 5 June 2020

\begin{abstract}
YerA41 is a Myoviridae bacteriophage that was originally isolated due its ability to infect Yersinia ruckeri bacteria, the causative agent of enteric redmouth disease of salmonid fish. Several attempts to determine its genomic DNA sequence using traditional and next generation sequencing technologies failed, indicating that the phage genome is modified in such a way that it is an unsuitable template for PCR amplification and for conventional sequencing. To determine the YerA41 genome sequence, we performed RNA-sequencing from phage-infected $Y$. ruckeri cells at different time points post-infection. The host-genome specific reads were subtracted and de novo assembly was performed on the remaining unaligned reads. This resulted in nine phage-specific scaffolds with a total length of $143 \mathrm{~kb}$ that shared only low level and scattered identity to known sequences deposited in DNA databases. Annotation of the sequences revealed 201 predicted genes, most of which found no homologs in the databases. Proteome studies identified altogether 63 phage particle-associated proteins. The RNA-sequencing data were used to characterize the transcriptional control of YerA41 and to investigate its impact on the bacterial gene expression. Overall, our results indicate that RNA-sequencing can be successfully used to obtain the genomic sequence of non-sequencable phages, providing simultaneous information about the phage-host interactions during the process of infection.
\end{abstract}

Keywords: YerA41; bacteriophage; RNA-sequencing; nucleotide modification; genome assembly; transcriptome; Yersinia ruckeri

\section{Introduction}

YerA41 is a bacteriophage that was originally isolated due its ability to infect Yersinia ruckeri bacteria, the causative agent of enteric redmouth disease of salmonid fish [1]. Bacteriophage YerA41 was first described in 1984 as a tailed icosahedral virus that lysed the vast majority of tested Y. ruckeri serovar I strains, and thus was believed to have a potential value for the diagnosis of redmouth disease. However, it was found that YerA41 has a relatively broad host range among Enterobacteriacae as it could infect some strains of other Yersinia species, Escherichia coli, Shigella flexneri, Enterobacter cloacae, Klebsiella and Erwinia spp. [1]. The YerA41 phage particles are large with heads of about $110 \mathrm{~nm}$ in diameter, $10 \times 8 \mathrm{~nm}$ necks, $250 \times 20 \mathrm{~nm}$ non-contracted sheaths and $70 \mathrm{~nm}$ long tail fibers [2]. Several attempts to sequence the YerA41 genome using next generation sequencing (Illumina) approaches failed previously. 
Additionally, it was observed that the phage DNA could not be digested by any of the numerous tested restriction enzymes. These results led to the conclusion that the phage DNA is modified in such a way that prevents the function of enzymes such as DNAP and DNA-modifying restriction enzymes. Indeed, preliminary analysis of the nucleosides confirmed the presence of modifications, however, without revealing their exact nature.

Naturally occurring modifications of the canonical deoxynucleotides can be found in the DNA of organisms from all domains of life. They may constitute only a small fraction of the bases or even replace the standard, un-modified base entirely [3]. Collectively, the greatest diversity of modified bases can be observed among bacteriophages. These modifications include both the types observed among the bacterial host species, and the more unusual that are not observed among different organisms [4]. A variety of different chemical groups can be attached to the nucleotide, ranging from simple methyl groups through amino acids, polyamines, monosaccharides to more complexed oligosaccharides. They do not lead to alterations in the specificity of base pairing, and primarily appear to be a part of the arms race between the infecting organism and its host. For example, these modifications can provide additional information needed for the control of gene expression, recognition of self and non-self DNA, or protection from enzymatic degradation and host defense mechanisms [3,4].

The hypermodified bases observed among phages include 5-hydroxymethylpyrimidines and their glycosylated derivatives, $\alpha$-putrescinylated and $\alpha$-glutamylated thymines, sugar-substituted 5-hydroxypentyl uracil, N6-(1-acetamido)-modified adenine and 7-methylguanine [3,5]. Interestingly, the hydroxymethyl deoxypyrimidines are produced from free nucleotides by phage-encoded deoxypyrimidine hydroxymethylases before their incorporation into DNA. This mechanism is different from the primary base methylations that are commonly catalyzed in situ on DNA. After incorporation, these hydroxymethylpyrimidines often undergo further modifications introduced by phage-encoded enzymes such as glycosyl- or acetyl-transferases [3,6,7].

Here, we have used RNA-sequencing to determine the nucleotide sequence of the phage YerA41 genome using its encoded transcripts. This approach allowed us to determine the nucleotide sequence of the greater part of the phage genome and to characterize its gene expression during infection. Additionally, our approach provided insight into the interactions between YerA41 and its host bacterium. Moreover, our results indicated that YerA41 represents a novel, previously unidentified, group of bacteriophages that at the level of nucleotide sequence shares almost no similarity with those previously reported.

\section{Materials and Methods}

\subsection{Bacterial Strains and Phage Propagation}

Bacteriophage YerA41 was propagated in Y. ruckeri strain RS41 [1] as described previously [8]. Y. ruckeri was grown in lysogeny broth (LB) at room temperature (RT, $22^{\circ} \mathrm{C}$ ). LB agar (LA) plates were used for all solid cultures and prepared by supplementing LB with $1.5 \%$ Bacto agar and $0.4 \%$ for soft agar. Bacteriophage YerA41 was stored at $-70{ }^{\circ} \mathrm{C}$ in tryptic soy broth (TSB) supplemented with $7 \%$ dimethyl sulfoxide (DMSO). The bacterial strains used in this study are listed in Table S1.

\subsection{Purification of Phage Particles}

The standard method for the production and purification of bacteriophages [9] was used. Briefly, an overnight culture of host bacteria was diluted 10-fold in TSB in a total volume of $1 \mathrm{~L}$ divided into four $2 \mathrm{~L}$ erlenmeyer flasks, $250 \mathrm{~mL}$ each, and infected with appropriate number of phage to reach the multiplicity of infection (MOI) of 1 . The infected cultures were incubated at $25{ }^{\circ} \mathrm{C}$ with vigorous aeration (250 rpm), until after 6-7 h the bacterial lysis took place. The lysed cultures were treated with DNase I (1.2 $\mu \mathrm{g} / \mathrm{mL}$; Roche Diagnostic, Mannheim, Germany) and RNase A (1 $\mu \mathrm{g} / \mathrm{mL}$; Sigma Chemicals, St. Louis, MO, USA) and incubated at RT for $30 \mathrm{~min}$. Solid $\mathrm{NaCl}$ was added to a final concentration of $1 \mathrm{M}$ and lysates were kept on ice for $1 \mathrm{~h}$, and then the solution was centrifuged at 
$11,000 \times g$ for $10 \mathrm{~min}$ at $4^{\circ} \mathrm{C}$ to remove the precipitated bacterial debris. The phage was recovered from the supernatant by precipitating with polyethylene glycol (PEG 8000) $\left(10 \%, w / v ;>60 \mathrm{~min} ; 0^{\circ} \mathrm{C}\right)$ and was resuspended into TM buffer (50 mM Tris- $\mathrm{HCl}, \mathrm{pH} 7.5,10 \mathrm{mM} \mathrm{MgSO} 4)$. Alternatively, the phage was purified from semiconfluent soft-agar plates as described [9]. The phage was further purified by chloroform extraction and one to three rounds of discontinuous glycerol density gradient ultracentrifugation at 35,000 rpm at $4{ }^{\circ} \mathrm{C}$ for $1 \mathrm{~h}$ in a Beckman SW41 rotor. After the centrifugations phages were resuspended in SM buffer (50 mM Tris- $\mathrm{HCl}$ pH 7.5, $100 \mathrm{mM} \mathrm{NaCl}, 8 \mathrm{mM} \mathrm{MgSO}, 0.01 \%$ gelatin) containing $8 \%$ of sucrose.

\subsection{One Step Growth Curve}

A mid-exponential-phase culture $\left(10 \mathrm{~mL}\right.$ ) of RS41 (optical density at $600 \mathrm{~nm}\left[\mathrm{OD}_{600}\right] 0.4$ to 0.5 ) was harvested by centrifugation at 3,000 rpm for $15 \mathrm{~min}$ and resuspended in $1 \mathrm{~mL}$ of TSB medium. YerA41 phage was added at MOI of 0.0005 and allowed to adsorb for $2 \mathrm{~min}$ at RT. The culture was then centrifuged, the pelleted bacterial cells were resuspended to $10 \mathrm{~mL}$ of TSB, and incubation was continued at RT. Samples $(100 \mu \mathrm{L})$ were taken at $10 \mathrm{~min}$ intervals. The first set of samples was immediately diluted and plated on lambda agar plates (per liter of broth: Bacto-agar 15 g; lambda broth per liter: tryptone $10 \mathrm{~g}, \mathrm{NaCl} 2.5 \mathrm{~g}$ ) for phage titration. In order to determine the eclipse period the second set of samples was treated with $1 \%$ chloroform before plating to release the intracellular phage particles $[10,11]$. The number of plaque forming units (PFU) in the immediately diluted 0 min time point samples was set to 1 to represent the number of infected cells in the experiment, and the PFU of all the other samples were normalized against that number. The burst size was then directly obtained from the normalized value after the rise period.

\subsection{Total RNA Extraction}

RNA extractions were carried out from three separate infection experiments. In the first experiment, the RS41 bacteria were grown for $16 \mathrm{~h}$ at RT and subsequently diluted 1:20 in fresh LB to a total volume of $20 \mathrm{~mL}$. When the $\mathrm{OD}_{600}$ of the culture reached 0.7 , duplicate $1 \mathrm{~mL}$ samples were withdrawn to represent $0 \mathrm{~min}$ uninfected samples, then $9 \mathrm{~mL}$ of the culture was infected with $1 \mathrm{~mL}$ of phage YerA41 stock $\left(5 \times 10^{10} \mathrm{pfu} / \mathrm{mL}\right)$ to achieve a MOI of ca. 50 . Duplicate $1 \mathrm{~mL}$ aliquots were withdrawn at 5,15 , and 30 min post-infection (p.i.). In the second experiment, the RS41 bacteria were grown for $16 \mathrm{~h}$ at RT and subsequently diluted 1:20 in fresh LB to a total volume of $20 \mathrm{~mL}$. When the $\mathrm{OD}_{600}$ of the culture reached $0.7,8.5 \mathrm{~mL}$ of the culture was infected with $1.5 \mathrm{~mL}$ of phage YerA41 stock to achieve a MOI of 10. One $\mathrm{mL}$ aliquots were withdrawn at 33, 45, 63, 75 and $92 \mathrm{~min}$ p.i. in one replicate each. In the third experiment, three biological replicates were grown for $16 \mathrm{~h}$ at RT and diluted 1:20 in $10 \mathrm{~mL}$. When the cultures reached $\mathrm{OD}_{600}$ of 0.6 , one $\mathrm{mL}$ aliquots were withdrawn from each culture, these representing the uninfected $0 \mathrm{~min}$ samples in triplicate. Then, to $5.3 \mathrm{~mL}$ of culture $0.7 \mathrm{~mL}$ of phage stock was added to reach a MOI of 50, mixed for $3 \mathrm{~min}$ followed by $3 \mathrm{~min}$ standing and 3 min centrifugation at $4500 \times g$ at $22{ }^{\circ} \mathrm{C}$. The supernatant was replaced with $6 \mathrm{~mL}$ fresh medium and triplicate $1 \mathrm{~mL}$ samples, one from each tube, were withdrawn at 15, 30 and 60 min p.i. In all experiments, total RNA was isolated from the samples using the SV Total RNA Isolation System (Promega, Madison, WI, USA) and the quality assessment was performed using LabChip (PerkinElmer, Waltham, MA, USA), using the DNA 5K/RNA/CZE chip with HT RNA Reagent Kit.

\subsection{RNA Sequencing}

The RNA-sequencing and data analysis were performed at the Nu-Omics DNA sequencing research facility at University of Northumbria. The rRNA was removed using Ribo-Zero ${ }^{\mathrm{TM}}$ rRNA Removal Kit for Gram-negative Bacteria (Illumina, San Diego, CA, USA). The sequencing library was prepared using the ScriptSeq-v2 RNA-Seq Library Preparation Kit (Illumina). Paired-end sequencing was performed on MiSeq (Illumina) with the read length of 150 nucleotides. 


\subsection{Transcriptome Assembly}

The obtained sequencing reads were quality filtered and aligned against Y. ruckeri PB-H2 chromosome (Acc.no. LN681231.1) and plasmids pYR2 (Acc.no. LN681229.1) and pYR3 (Acc.no. LN681230.1) using Bowtie2 aligner [12]. The reads that failed to align to these reference sequences were merged together and assembled using Velvet [13] and SPAdes [14]. The obtained assembled sequences were blasted against the NCBI nucleotide collection (https://blast.ncbi.nlm.nih.gov/Blast.cgi) and contigs that showed high sequence identity to Yersinia strains were excluded. The phage genomic scaffolds were auto-annotated using Rapid Annotation Using Subsystem Technology (RAST, http://rast.nmpdr.org/) and the obtained annotation was validated manually using the Artemis tool [15]. Presence of suitable ribosomal binding sites in front of start codons of each predicted gene was confirmed manually. The tRNA genes were identified using the ARAGORN (http://130.235.46.10/ARAGORN/) and tRNA-SCAN (http://lowelab.ucsc.edu/tRNAscan-SE/index.html) tools.

\subsection{RNA-Sequencing Data Analysis}

The quality filtered sequencing reads from different time points were aligned against the obtained YerA41 assembly scaffolds and against the Y. ruckeri PB-H2 reference sequence using Bowtie2 aligner [12]. The reads aligning over each gene were counted using the HTSeq [16]. The differential gene expression of bacterial transcriptome was analyzed using the edgeR [17].

\subsection{Proteome Analysis}

Purified phages were concentrated by centrifugation for $2 \mathrm{~h}$ at $4{ }^{\circ} \mathrm{C}$ at $16,000 \times g$. Prior to the digestion of proteins to peptides with trypsin, the proteins in the samples were reduced with tris (2-carboxyethyl)phosphine (TCEP) and alkylated with iodoacetamide. Tryptic peptide digests were purified using C18 reversed-phase chromatography columns [18] and the mass spectrometry (MS) analysis was performed on an Orbitrap Elite Electron-Transfer Dissociation (ETD) mass spectrometer (Thermo Scientific, Waltham, MA, USA), using Xcalibur version 2.2, coupled to an Thermo Scientific nLC1000 nanoflow High Pressure Liquid Chromatography (HPLC) system. Peak extraction and subsequent protein identification was achieved using Proteome Discoverer 1.4 software (Thermo Scientific). Calibrated peak files were searched against the YerA41 and Y. ruckeri PB-H2 chromosome and plasmid proteins by a SEQUEST search engine. Error tolerances on the precursor and fragment ions were $\pm 15 \mathrm{ppm}$ and $\pm 0.8 \mathrm{Da}$, respectively. For peptide identification, a stringent cut-off ( 0.05 false discovery rate or 5\%) was used. The LC-MS/MS was performed at the Proteomics Unit, Institute of Biotechnology, University of Helsinki.

\subsection{DNA Isolation}

Phage DNA was obtained from high-titer phage preparations as described [9] using proteinase K plus SDS treatment followed by phenol-chloroform extractions and ethanol precipitation.

\subsection{Accession Numbers}

The RNA sequence data were deposited to the Gene Expression Omnibus (Acc. no GSE146319). 


\section{Results}

\subsection{Characterization of YerA41}

The growth curve of YerA41 propagated in Y. ruckeri RS41 is shown in Figure S1. Apparent eclipse and latent periods of 30 and $40 \mathrm{~min}$, respectively, were followed by a rise period of $20 \mathrm{~min}$, and the burst size was 138 PFU per infected cell. The host range of YerA41 was studied on bacteria grown both at RT and at $37^{\circ} \mathrm{C}$, as temperature is known to regulate surface structures in the genus Yersinia [19]. Altogether, 129 strains representing 9 different Yersinia species and 3 other genera were used (Table 1 and Table S1). All Y. enterocolitica strains except for those of serotype O:8 were resistant to YerA41. Most tested Y. intermedia and Y. ruckeri strains were sensitive to YerA41 phage at both tested temperatures. In addition, many Y. kristenseni strains, and the Shigella flexneri strain, were sensitive to YerA41 (Table 1). Such a broad host range indicates that the phage uses a conserved bacterial surface structure as a receptor.

Table 1. Host range of bacteriophage YerA41 (numbers of studied strains for each species and serotype are given in parenthesis). The sensitivity was tested both at RT and at $37^{\circ} \mathrm{C}$.

\begin{tabular}{|c|c|c|c|}
\hline Bacterial Species & $\begin{array}{l}\text { YerA41 Sensitive } \\
\text { Serotypes }\end{array}$ & $\begin{array}{c}\text { YerA41 } \\
\text { Sensitive Serotypes } \\
\text { at } 37^{\circ} \mathrm{C}\end{array}$ & $\begin{array}{c}\text { YerA41 } \\
\text { Resistant Serotypes or Strains }\end{array}$ \\
\hline Yersinia enterocolitica & $\mathrm{O}: 8(5)$ & O:8 (5) & $\begin{array}{c}\text { O:1(2),O:1,2,3(1), O:2(2), O:3(2), O:4(1), } \\
\text { O:4,32(2), O:5(3), O:5,27(2), O:6(2), } \\
\text { O:6,30(2), O:6,31(2), O:7,8(8), O:9(2), } \\
\text { O:13,17(1), O:13,7(2), O:13a,13b(2), } \\
\text { O:14(1), O:15(2) O:20(2), O:21(2), } \\
\text { O:25(1), O:25,26(1), O:26,44(1), } \\
\text { O:28,50(1), O:34 (1), O:35,36 (1), } \\
\text { O:35,52(1), O:41(27)43(2), O:41(27)42 } \\
\text { K1(1), O:50(2), O:41(27)K1(1), O:41,43(1), } \\
\text { K1 non-typable (2), non-typable(4) }\end{array}$ \\
\hline $\begin{array}{c}\text { Yersinia } \\
\text { pseudo-tuberculosis }\end{array}$ & - & - & $\begin{array}{c}\text { O:1(1), O:1a(1), O:1b(1), O:2 (2), O:2a(1), } \\
\text { O:2b(1), O:2c(1), O:3 (2), O:4a (1), O:4b } \\
\text { (1), O:5a (1), O:5b(1), O:6 (1), O:7 (1), O:8 } \\
\text { (1), O:9(1), }\end{array}$ \\
\hline Yersinia frederikseni & - & $\mathrm{O}: 16(1), \mathrm{O}: 35(1)$ & O:48 (1), non-typable (4) \\
\hline Yersinia intermedia & O:16,21(1), O:52,54 (1) & $\mathrm{O}: 16,21(1)$ & $-n^{2}-1$ \\
\hline Yersinia kristenseni & $\begin{array}{c}\text { O:12,25(1), O:16(2), } \\
\text { non-typable (1) }\end{array}$ & $\begin{array}{l}\text { O:12.25(1), O:16(2), } \\
\text { non-typable (1) }\end{array}$ & non-typable(1) \\
\hline Yersinia mollareti & - & - & $\mathrm{O}: 59(20,36,7)(1)$ \\
\hline Yersinia pestis & - & - & $(2)$ \\
\hline Yersinia bercoveri & - & - & O:58,16(1), non-typable(1) \\
\hline Yersinia ruckeri & (2) & $(2)$ & - \\
\hline Providencia rettgeri & - & - & $(1)$ \\
\hline Salmonella typhimurium & - & - & (1) \\
\hline Shigella flexneri & $(1)$ & (1) & - \\
\hline
\end{tabular}

\subsection{Genome Analysis}

The RNA-sequencing reads not aligned to the Y. ruckeri reference genome were de novo assembled; the obtained unique contigs with no sequence similarity to Yersinia species were scaffolded (Figure 1). This resulted in nine qualified scaffolds comprising altogether 143,296 bp (Table 2, Figure 2). The overall GC ratio of the YerA41 genome was 32.3\%. Importantly, the scaffolds did not present any significant overall identity to nucleotide sequences stored in databases. 


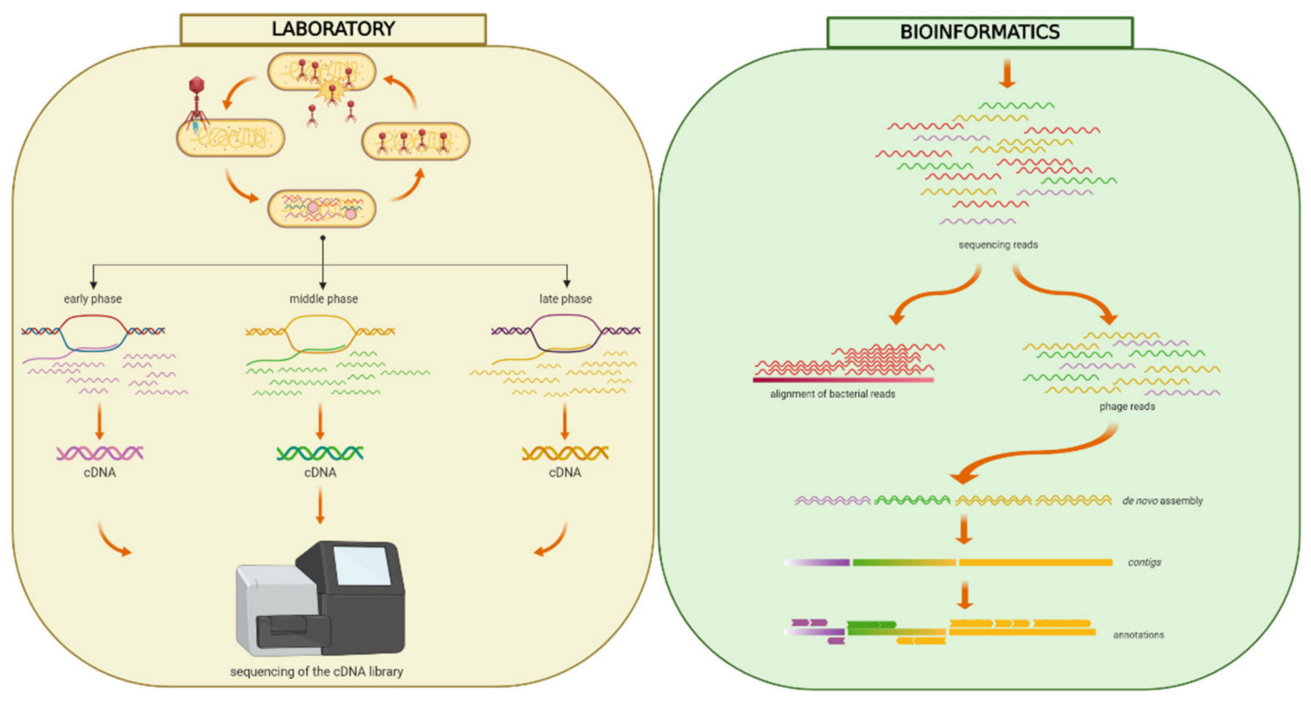

Figure 1. Workflow of the RNA-seq approach. Freshly diluted Y. ruckeri RS41 bacteria were grown until $\mathrm{OD}_{600}=0.6$ and then infected with phage YerA41 at MOI equal to 10 or 50. The culture was washed with LB to remove the unbound phage particles, and thus prevent re-infection of bacterial cells at later stages of the experiment. Samples for RNA isolation were taken at different time points p.i. $(0,5,15,33,45,63,75,92 \mathrm{~min})$. After the removal of bacterial rRNA, the prepared libraries were sequenced. The obtained sequencing reads were quality filtered and aligned against $Y$. ruckeri $\mathrm{PBH} 2$ chromosome (Acc.no. LN681231.1) and plasmids pYR2 (Acc.no. LN681229.1) and pYR3 (Acc.no. LN681230.1). The reads that failed to align to these reference sequences were merged together and assembled using Velvet [13] and SPAdes [14]. The obtained assembled sequences were blasted against the NCBI nucleotide collection and contigs showing high identity rates with Yersinia strains were excluded. The phage genomic scaffolds were auto-annotated using Rapid Annotation Using Subsystem Technology (RAST) [20]. Presence of suitable ribosomal binding sites in front of each predicted start codon was confirmed. Figure was created using BioRender (https://app.biorender.com).

A total of 201 putative genes were detected by RAST analysis and manual annotation. Predicted functions could be assigned to 60 of the 201 gene products, the others showed no significant similarity to any protein sequences in the databases (Table 3 and Table S2). The predicted YerA41 gene products showed similarity to DNA polymerases (Gp061, Gp097, Gp137, Gp0195) and RNA polymerase $\beta-, \beta^{\prime}-$ and other subunits (Gp019, Gp054, Gp055, Gp056, Gp162), helicases (Gp143, Gp145, Gp193), topoisomerases (Gp135, Gp136, Gp190), and a DNA ligase (Gp199). In addition, the predicted genes encode for enzymes involved in nucleoside metabolism, including 5'-deoxynucleotidase (Gp060), dCTP deaminase (Gp114), dUTP diphosphatase (Gp141), thymidylate synthetase (Gp127), ribonucleoside-diphosphate reductase (Gp110), ribonucleotide reductase (Gp109), and several endo- and exo-nucleases (Gp126, Gp149, Gp167, Gp179, Gp180, Gp189). The other gene products with recognizable function encoded different phage structural proteins. Three tRNA genes encoding tRNA-Arg, tRNA-Met, and tRNA-Leu, were identified by both ARAGORN and tRNA-SCAN, all located in a module on the scaffold_3. Finally, the gene g064-g070 products showed similarity to UDP-GlcNAc 2-epimerase, SDR family oxidoreductases, polysaccharide deacetylase, 2-C-methyl-D-erythritol-4-phosphate cytidylyltransferase, and glycerophosphodiester phosphodiesterase, suggesting them roles in biosynthesis of sugar-modified nucleotides. 


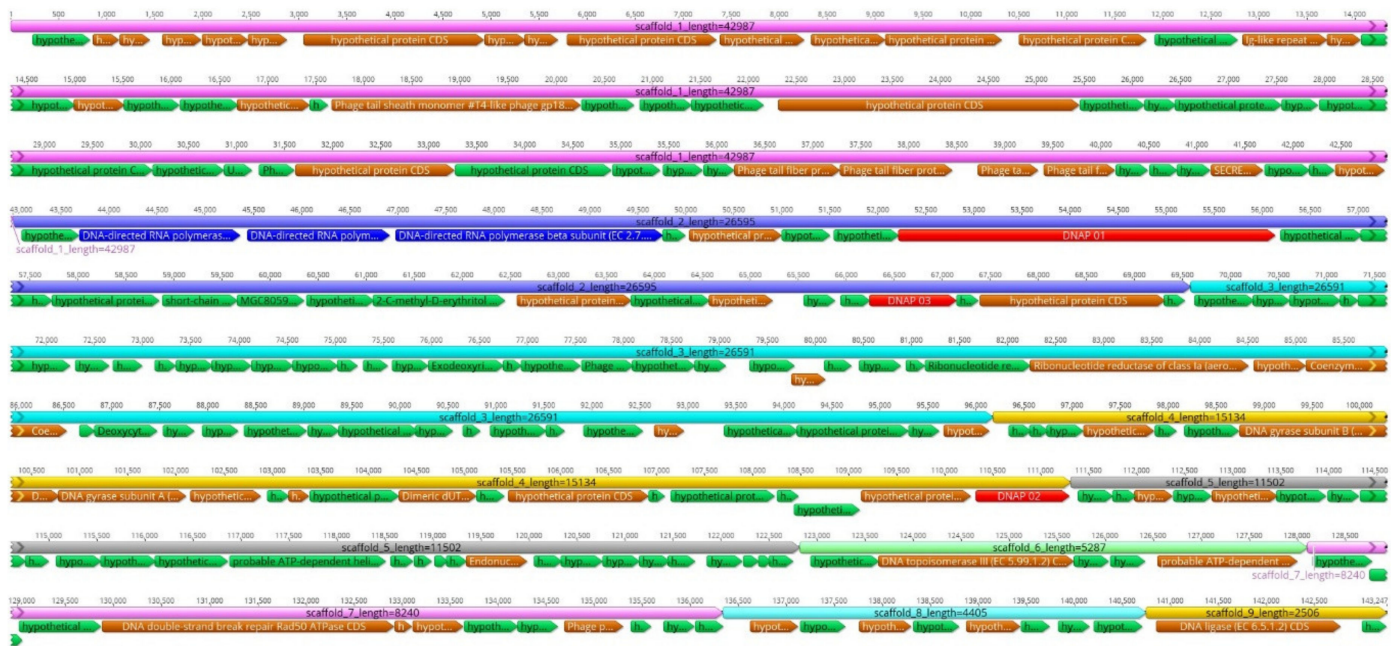

Figure 2. Gene organization of the nine scaffolds of the phage YerA41 genome. The scaffolds are organized based on size. The gene colors indicate predicted functions of their products: Green, hypothetical proteins; Blue, RNA polymerase subunits; Red, DNA polymerase-like proteins; Brown, phage particle associated (structural) proteins. The figure was generated using Geneious 10.2.6 (www.geneious.com).

Table 2. The assembled scaffolds of YerA41 genome. The numbering of the scaffolds is based on their length and does not reflect their actual position in the phage genome.

\begin{tabular}{ccc}
\hline ID & Size [bp] & GC\% \\
\hline scaffold_1 & 42987 & 34.5 \\
scaffold_2 & 27377 & 31.6 \\
scaffold_3 & 26591 & 31.7 \\
scaffold_4 & 15134 & 32.0 \\
scaffold_5 & 11502 & 32.8 \\
scaffold_6 & 8240 & 29.6 \\
scaffold_7 & 5287 & 28.9 \\
scaffold_8 & 3672 & 29.6 \\
scaffold_9 & 2506 & 29.6 \\
\hline TOTAL/Average: & $\mathbf{1 4 3 2 9 6}$ & $\mathbf{3 2 . 3}$ \\
\hline
\end{tabular}

\subsection{Proteomic Analysis of the Phage Structural Proteins}

To determine the phage particle associated and structural proteins, a proteomic analysis of the purified phage particles using LC-MS/MS was carried out. The structural proteins were identified through the comparative analysis of the obtained tryptic peptide sequence patterns and the sequence-based in silico determined tryptic peptide sequences of phage proteins. Altogether, 63 phage proteins were reliably identified in the LC-MS/MS analysis (Table S2). The analysis revealed among the identified proteins structural proteins such as major capsid, tail sheath, baseplate wedge, tail fiber, and tail fiber assembly proteins. In addition, several DNA- or RNA modifying enzymes, such as DNA polymerases, helicases, recombinases, topoisomerases, endo- and exonucleases, and RNA polymerase subunits and a sigma factor were phage particle associated proteins (PPAPs, Table S2). These are likely to be injected into the bacteria along with the genomic DNA to take over the host metabolism as soon as possible after infection (Table S2).

\subsection{Temporal Expression of Phage Genes}

The heatmap of YerA41 genes expressed at different time points revealed evident temporal gene expression (Figure 3). The mean values of expression of early (5-15 min p.i.), middle (33-45 min), and late (63-92 $\mathrm{min}$ ) were calculated and compared between each other. A gene was assigned to certain 
class based on the post infection time when its expression peaked (Table 3 and Table S2). In total 47 genes (23.4\% of phage putative genes) had their highest expression in the first min post infection. The function of the majority of the gene products remained unknown, yet six of the gene products were predicted to be involved in nucleic acid processing. Interestingly, the genes of the early phase were scattered across several scaffolds. The heatmap (Figure 3) shows that the YerA41 gene expression progresses rapidly and indistinctly to the middle phase. This phase was characterized by the expression of $101(50.2 \%)$ genes, including numerous genes presumably involved in nucleic acid metabolism. During the latest state of infection, 51 (25.4\%) genes were induced. According to the in silico analysis, the majority of these genes encode for the structural proteins of phage particles. The remaining two putative genes (the g200 and g201 genes) showed minimal expression with no changes throughout the course of infection; thus, it is highly probable that they constitute bioinformatics artifacts.

Table 3. Temporal expression profiles of the gene products of phage YerA41 having predicted functions. The full list of all gene products, including the hypothetical proteins of unknown function, is presented in Supplementary Table S2. The LC-MS/MS-identified PPAPs are marked with asterisk.

\begin{tabular}{|c|c|c|c|}
\hline Temporal Expression & Gene ID & Scaffold & $\begin{array}{l}\text { Putative Functions of Gene Products Based on } \\
\text { Database Similarity }\end{array}$ \\
\hline \multirow[t]{15}{*}{ Early } & $g 054$ & 2 & DNA directed RNA polymerase, subunit* \\
\hline & g055 & 2 & DNA-directed RNA polymerase, subunit ${ }^{*}$ \\
\hline & $g 056$ & 2 & DNA-directed RNA polymerase \\
\hline & g078 & 2 & Lytic transglycosylase \\
\hline & $g 097$ & 3 & DNA polymerase III, subunit \\
\hline & $g 116$ & 3 & RNA 2'-phosphotransferase \\
\hline & g126 & 3 & Endonuclease-like protein \\
\hline & g135 & 4 & DNA topoisomerase* \\
\hline & $g 161$ & 5 & Tail fiber protein \\
\hline & $g 162$ & 5 & $\begin{array}{l}\text { DNA directed RNA polymerase, subunit / Putative } \\
\text { DNA helicase }\end{array}$ \\
\hline & $g 189$ & 7 & Endonuclease-like protein \\
\hline & g190 & 7 & DNA topoisomerase* \\
\hline & g193 & 7 & Helicase $^{*}$ \\
\hline & g195 & 8 & DNA polymerase \\
\hline & g199 & 9 & DNA ligase $^{*}$ \\
\hline \multirow[t]{25}{*}{ Middle } & $g 060$ & 2 & 5'-deoxynucleotidase \\
\hline & $g 061$ & 2 & DNA polymerase* \\
\hline & $g 064$ & 2 & UDP-GlcNAc 2-epimerase \\
\hline & g065 & 2 & Oxidoreductase \\
\hline & $g 066$ & 2 & SDR family oxidoreductase \\
\hline & $g 067$ & 2 & Polysaccharide deacetylase \\
\hline & $g 068$ & 2 & $\begin{array}{l}\text { 2-C-methyl-D-erythritol 4-phosphate } \\
\text { cytidylyltransferase (EC 2.7.7.60) }\end{array}$ \\
\hline & $g 070$ & 2 & Glycerophosphodiester phosphodiesterase \\
\hline & g109 & 3 & Ribonucleotide reductase \\
\hline & $g 110$ & 3 & Ribonucleoside-diphosphate reductase subunit alpha* \\
\hline & g112 & 3 & Ribosomal protein modification protein $*$ \\
\hline & g114 & 3 & dCTP deaminase \\
\hline & $g 127$ & 3 & Thymidylate synthetase \\
\hline & g133 & 4 & Transglycosylase \\
\hline & g136 & 4 & DNA topoisomerase ${ }^{*}$ \\
\hline & g137 & 4 & DNA polymerase III, subunit* \\
\hline & $g 140$ & 4 & Structural protein \\
\hline & g141 & 4 & dUTP diphosphatase ${ }^{*}$ \\
\hline & $g 143$ & 4 & ATP-dependent DNA helicase ${ }^{*}$ \\
\hline & $g 145$ & 4 & Replicative helicase \\
\hline & g149 & 4 & Exodeoxyribonuclease ${ }^{*}$ \\
\hline & $g 167$ & 5 & Endonuclease ${ }^{*}$ \\
\hline & $g 174$ & 5 & Phage baseplate assembly protein \\
\hline & $g 179$ & 6 & Exonuclease \\
\hline & $g 180$ & 6 & Exonuclease $^{*}$ \\
\hline
\end{tabular}


Table 3. Cont.

\begin{tabular}{llll}
\hline Temporal Expression & Gene ID & Scaffold & $\begin{array}{l}\text { Putative Functions of Gene Products Based on } \\
\text { Database Similarity }\end{array}$ \\
\hline Late & $g 007$ & 1 & DNA packaging terminase* \\
$g 012$ & 1 & Prohead core protein protease* \\
& $g 014$ & 1 & Capsid protein* \\
$g 016$ & 1 & Sugar binding protein* \\
& $g 019$ & 1 & RNA polymerase sigma factor* \\
$g 024$ & 1 & Phage tail sheath protein* \\
$g 025$ & 1 & Tail protein \\
$g 028$ & 1 & Tail family protein* \\
$g 031$ & 1 & Tail protein \\
$g 032$ & 1 & Tail protein \\
$g 034$ & 1 & Tail-associated lysozyme \\
$g 035$ & 1 & Tail-associated lysozyme \\
& $g 037$ & 1 & Baseplate wedge protein* \\
$g 040$ & 1 & Capsid protein \\
$g 041$ & 1 & Virion structural protein \\
& $g 042$ & 1 & Baseplate wedge protein* \\
& $g 043$ & 1 & Tail fiber protein* \\
$g 044$ & 1 & Phage tail fiber assembly protein* \\
& $g 045$ & 1 & Tail fiber protein* \\
$g 049$ & 1 & Endolysin* \\
\hline
\end{tabular}

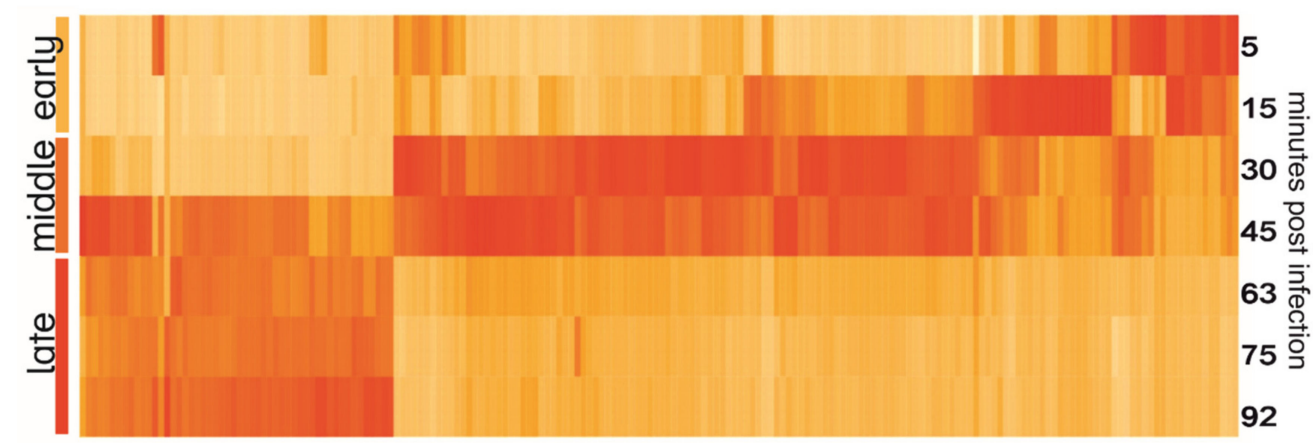

Figure 3. Heatmap of YerA41 genes expressed at different time points post infection. Gene expression values were normalized to the highest expression to show the timing of expression; therefore, the intensity of color on the heatmap reflects the difference of expression of one gene at different time points, yet not the difference of expression between different genes.

\subsection{Bacterial Response to Lytic Infection}

It is crucial to get insight into different phases of phage infection in order to understand the bacterial host response. Based on the one-step growth curve and the results of short time interval RNA-sequencing, three different time points: 15,30 , and $60 \mathrm{~min}$ p.i. were chosen as the representative timepoints for early, middle, and late stages of infection. Analysis of the RNA-sequencing data from three independent biological replicates revealed that $Y$. ruckeri differentially regulated the expression of 167 genes during the early stage of infection (15 min p.i.). Among the differentially expressed genes of the bacterial host (4.6\%), 38\% of the genes showed upregulation, and the remaining $62 \%$ showed downregulation (Table 4). Most of the upregulated genes encoded products implicated in the protection of bacterial cells from oxidative damage. These included genes encoding catalase (CSF007_12285), thioredoxin (CSF007_14055), glutaredoxin (CSF007_6685), peroxiredoxin family protein (CSF007_17480), glutathione reductase (CSF007_0665), and thioredoxin reductase (CSF007_6870). Additionally, RNA-sequencing showed the induction of genes involved in glycolysis, namely the genes encoding dihydrolipoamide dehydrogenase (CSF007_17485), glucose-6-phosphate isomerase (CSF007_16360), and pyruvate kinase (CSF007_9590), as well as three genes involved in the biosynthesis of siderophores (CSF007_15200, CSF007_15205, CSF007_15210). Among the host bacterium genes 
presenting the strongest upregulation p.i. was dps (CSF007_6300), which encodes a non-specific DNA-binding protein involved in DNA protection during exposure to severe environmental insult. An increase in expression was also observed for host bacterium genes involved in the biosynthesis of antibacterial agents like polymyxin and enterobactin (CSF007_15260, CSF007_15255, CSF007_15265). In contrast, the bacteria downregulated genes that are involved in the metabolism of different carbohydrates, as well as several genes encoding the succinate dehydrogenase complex (CSF007_5810, CSF007_5800,CSF007_5795, CSF007_5805).

Table 4. Transcriptional response of $Y$. ruckeri to infection with YerA41. The list of bacterial genes showing significant $(p$-value $<0.001)$ differential expression at both $15 \mathrm{~min}$ and $30 \mathrm{~min}$ time points compared to non-infected bacteria. The lists of genes differentially expressed at different time points $(15,30$ and 60 min p.i.) are presented in Supplementary Table S3. LogFC; log-ratio of a transcript's expression values in two different conditions. FDR; False Discovery Rate.

\begin{tabular}{|c|c|c|c|c|c|}
\hline \multirow{2}{*}{ Gene ID } & \multirow{2}{*}{ Function } & \multicolumn{2}{|c|}{$15 \mathrm{~min}$} & \multicolumn{2}{|c|}{$30 \mathrm{~min}$} \\
\hline & & $\operatorname{logFC}$ & FDR & $\log \mathrm{FC}$ & FDR \\
\hline CSF007_17485 & $\begin{array}{l}\text { Dihydrolipoamide } \\
\text { dehydrogenase }\end{array}$ & 7.07 & $1.97 \times 10^{-146}$ & 1.28 & $2.16 \times 10^{-07}$ \\
\hline CSF007_17480 & $\begin{array}{l}\text { Peroxiredoxin family } \\
\text { protein/glutaredoxin }\end{array}$ & 6.95 & $4.94 \times 10^{-128}$ & 1.12 & $7.36 \times 10^{-05}$ \\
\hline CSF007_6300 & $\begin{array}{c}\text { Non-specific DNA-binding } \\
\text { protein Dps / Iron-binding } \\
\text { ferritin-like antioxidant protein / } \\
\text { Ferroxidase }\end{array}$ & 4.39 & $4.13 \times 10^{-66}$ & 1.90 & $5.48 \times 10^{-11}$ \\
\hline CSF007_12285 & Catalase & 4.10 & $3.26 \times 10^{-59}$ & 1.54 & $9.40 \times 10^{-09}$ \\
\hline CSF007_9590 & Pyruvate kinase & 1.95 & $7.27 \times 10^{-15}$ & 2.11 & $9.00 \times 10^{-13}$ \\
\hline CSF007_11760 & Putrescine importer & 1.43 & $1.44 \times 10^{-07}$ & 1.71 & $4.96 \times 10^{-05}$ \\
\hline CSF007_5840 & $\begin{array}{l}\text { Cytochrome d ubiquinol oxidase } \\
\text { subunit I }\end{array}$ & 1.21 & $1.89 \times 10^{-06}$ & 1.49 & 0.00011 \\
\hline CSF007_5845 & $\begin{array}{l}\text { Cytochrome d ubiquinol oxidase } \\
\text { subunit II }\end{array}$ & 1.14 & $1.98 \times 10^{-06}$ & 1.48 & $2.78 \times 10^{-05}$ \\
\hline CSF007_13405 & $\begin{array}{c}\text { Inosine-5-monophosphate } \\
\text { dehydrogenase }\end{array}$ & 0.91 & 0.00034 & 1.19 & 0.00017 \\
\hline CSF007_12920 & hypothetical protein & 0.88 & 0.00014 & 1.11 & 0.00015 \\
\hline CSF007_5505 & hypothetical protein & -0.78 & $1.77 \times 10^{-05}$ & -1.18 & $1.44 \times 10^{-05}$ \\
\hline CSF007_14715 & Glycine cleavage system $\mathrm{H}$ protein & -0.81 & 0.00044 & -1.88 & $3.38 \times 10^{-07}$ \\
\hline CSF007_9025 & Alkyl sulfatase & -0.93 & $2.94 \times 10^{-06}$ & -1.32 & $1.03 \times 10^{-05}$ \\
\hline CSF007_13885 & D-ribulokinase & -0.94 & $6.94 \times 10^{-07}$ & -2.04 & $9.33 \times 10^{-14}$ \\
\hline CSF007_13880 & $\begin{array}{l}\text { Phosphosugar isomerase/binding } \\
\text { protein }\end{array}$ & -1.01 & $2.19 \times 10^{-06}$ & -1.98 & $6.52 \times 10^{-09}$ \\
\hline CSF007_1760 & Aspartate ammonia-lyase & -1.02 & $6.88 \times 10^{-05}$ & -1.98 & $3.86 \times 10^{-12}$ \\
\hline CSF007_0675 & Oligopeptidase A & -1.03 & 0.00043 & -1.29 & 0.00043 \\
\hline CSF007_9680 & Hemin transport protein HmuS & -1.06 & $1.77 \times 10^{-05}$ & -1.38 & 0.00097 \\
\hline CSF007_17975 & Glutamine synthetase type I & -1.09 & 0.00014 & 1.92 & $4.07 \times 10^{-05}$ \\
\hline CSF007_14720 & $\begin{array}{l}\text { Aminomethyltransferase (glycine } \\
\text { cleavage system } \mathrm{T} \text { protein) }\end{array}$ & -1.11 & $3.59 \times 10^{-09}$ & -1.69 & $7.18 \times 10^{-10}$ \\
\hline CSF007_11035 & $\begin{array}{l}\text { Transcriptional repressor of PutA } \\
\text { and PutP / Proline dehydrogenase } \\
\text { (Proline oxidase) / } \\
\text { Delta-1-pyrroline-5-carboxylate } \\
\text { dehydrogenase }\end{array}$ & -1.12 & $9.24 \times 10^{-06}$ & -2.14 & $5.30 \times 10^{-14}$ \\
\hline CSF007_13080 & NADP-dependent malic enzyme & -1.12 & $9.98 \times 10^{-08}$ & -1.68 & $2.82 \times 10^{-09}$ \\
\hline CSF007_6400 & $\begin{array}{c}\text { Galactose/methyl galactoside ABC } \\
\text { transport system ATP-binding } \\
\text { protein MglA }\end{array}$ & -1.13 & $1.92 \times 10^{-07}$ & -1.72 & $6.99 \times 10^{-09}$ \\
\hline CSF007_0690 & Universal stress protein A & -1.20 & $1.55 \times 10^{-07}$ & -1.56 & $5.98 \times 10^{-06}$ \\
\hline CSF007_0605 & $\begin{array}{c}\text { Aerobic C4-dicarboxylate } \\
\text { transporter for fumarate/L-malate/ } \\
\text { D-malate/succunate }\end{array}$ & -1.23 & $1.07 \times 10^{-09}$ & -1.09 & 0.00046 \\
\hline
\end{tabular}


Table 4. Cont.

\begin{tabular}{|c|c|c|c|c|c|}
\hline \multirow{2}{*}{ Gene ID } & \multirow{2}{*}{ Function } & \multicolumn{2}{|c|}{$15 \mathrm{~min}$} & \multicolumn{2}{|c|}{$30 \mathrm{~min}$} \\
\hline & & $\log \mathrm{FC}$ & FDR & $\log \mathrm{FC}$ & FDR \\
\hline CSF007_1210 & Cyclic AMP receptor protein & -1.32 & $5.98 \times 10^{-08}$ & -1.42 & $1.30 \times 10^{-05}$ \\
\hline CSF007_0245 & 16 kDa heat shock protein A & -1.37 & 0.00033 & -1.80 & $6.55 \times 10^{-06}$ \\
\hline CSF007_5820 & $\begin{array}{l}\text { Dihydrolipoamide } \\
\text { succinyltransferase component } \\
\text { (E2) of 2-oxoglutarate } \\
\text { dehydrogenase complex }\end{array}$ & -1.41 & $7.97 \times 10^{-08}$ & -2.87 & $1.10 \times 10^{-12}$ \\
\hline CSF007_18075 & $\begin{array}{c}\text { Ribose } A B C \text { transport system } \\
\text { periplasmic ribose-binding } \\
\text { protein RbsB }\end{array}$ & -1.41 & $1.96 \times 10^{-11}$ & -1.57 & $8.42 \times 10^{-07}$ \\
\hline CSF007_16000 & hypothetical protein & -1.42 & $2.65 \times 10^{-06}$ & -1.99 & $6.12 \times 10^{-06}$ \\
\hline CSF007_11865 & Mannonate dehydratase & -1.46 & $8.78 \times 10^{-10}$ & -2.13 & $6.04 \times 10^{-12}$ \\
\hline CSF007_13895 & $\begin{array}{l}\text { Ribose } A B C \text { transport system } \\
\text { permease protein } \mathrm{RbsC}\end{array}$ & -1.48 & $1.29 \times 10^{-12}$ & -2.07 & $7.16 \times 10^{-12}$ \\
\hline CSF007_0935 & $\begin{array}{l}\text { Transcriptional activator of } \\
\text { maltose regulon MalT }\end{array}$ & -1.49 & $7.07 \times 10^{-14}$ & -1.48 & $8.42 \times 10^{-07}$ \\
\hline CSF007_16315 & $\begin{array}{l}\text { Maltose operon periplasmic } \\
\text { protein MalM }\end{array}$ & -1.51 & $6.85 \times 10^{-06}$ & -2.03 & 0.00043 \\
\hline CSF007_18085 & $\begin{array}{l}\text { Ribose ABC transport system } \\
\text { ATP-binding protein RbsA }\end{array}$ & -1.51 & $7.72 \times 10^{-10}$ & -1.85 & $2.56 \times 10^{-06}$ \\
\hline CSF007_9675 & $\begin{array}{l}\text { TonB-dependent hemin } \\
\text { ferrichrome receptor }\end{array}$ & -1.55 & $9.46 \times 10^{-16}$ & -1.13 & 0.00018 \\
\hline CSF007_5825 & $\begin{array}{l}\text { Succinyl-CoA ligase } \\
\text { [ADP-forming] beta chain }\end{array}$ & -1.60 & $7.19 \times 10^{-08}$ & -2.86 & $5.80 \times 10^{-10}$ \\
\hline CSF007_5830 & $\begin{array}{l}\text { Succinyl-CoA ligase } \\
\text { [ADP-forming] alpha chain }\end{array}$ & -1.63 & $1.56 \times 10^{-09}$ & -3.01 & $4.78 \times 10^{-14}$ \\
\hline CSF007_18090 & $\begin{array}{l}\text { Ribose } A B C \text { transport system high } \\
\text { affinity permease RbsD }\end{array}$ & -1.66 & $1.10 \times 10^{-11}$ & -2.16 & $4.82 \times 10^{-08}$ \\
\hline CSF007_16340 & $\begin{array}{l}\text { Maltose/maltodextrin } \mathrm{ABC} \\
\text { transporter substrate binding } \\
\text { periplasmic protein MalE }\end{array}$ & -1.68 & $5.91 \times 10^{-08}$ & -2.03 & $1.45 \times 10^{-06}$ \\
\hline CSF007_3355 & Aconitate hydratase 2 & -1.69 & $3.40 \times 10^{-12}$ & -1.66 & $1.56 \times 10^{-06}$ \\
\hline CSF007_5815 & $\begin{array}{l}\text { 2-oxoglutarate dehydrogenase E1 } \\
\text { component }\end{array}$ & -1.80 & $2.19 \times 10^{-13}$ & -2.96 & $3.74 \times 10^{-18}$ \\
\hline CSF007_9550 & Putative transport protein & -1.80 & $4.34 \times 10^{-12}$ & -1.51 & $2.19 \times 10^{-06}$ \\
\hline CSF007_16325 & $\begin{array}{l}\text { Maltose/maltodextrin transport } \\
\text { ATP-binding protein MalK }\end{array}$ & -1.81 & $6.80 \times 10^{-06}$ & -2.93 & $3.65 \times 10^{-08}$ \\
\hline CSF007_9650 & Phosphoenolpyruvate synthase & -1.82 & $6.56 \times 10^{-15}$ & -2.54 & $1.16 \times 10^{-09}$ \\
\hline CSF007_11875 & D-mannonate oxidoreductase & -1.87 & $3.62 \times 10^{-13}$ & -2.57 & $4.08 \times 10^{-14}$ \\
\hline CSF007_12965 & $\begin{array}{c}\text { Sialic acid transporter (permease) } \\
\text { NanT }\end{array}$ & -1.92 & $2.90 \times 10^{-12}$ & -2.72 & $4.08 \times 10^{-14}$ \\
\hline CSF007_13900 & $\begin{array}{l}\text { Ribose/xylose/arabinose/galactoside } \\
\text { ABC-type transport system } \\
\text { ATP-binding protein }\end{array}$ & -2.08 & $2.79 \times 10^{-28}$ & -2.06 & $7.97 \times 10^{-05}$ \\
\hline CSF007_6395 & $\begin{array}{c}\text { Galactose/methyl galactoside } \mathrm{ABC} \\
\text { transport system } \\
\text { galactose-binding periplasmic } \\
\text { protein MglB }\end{array}$ & -2.08 & $2.72 \times 10^{-14}$ & -2.79 & $1.40 \times 10^{-17}$ \\
\hline CSF007_11455 & hypothetical protein & -2.12 & $8.23 \times 10^{-28}$ & -1.57 & $4.48 \times 10^{-05}$ \\
\hline CSF007_0865 & Gluconokinase & -2.12 & $9.37 \times 10^{-17}$ & -1.80 & $7.28 \times 10^{-06}$ \\
\hline CSF007_12460 & membrane protein & -2.21 & $3.34 \times 10^{-18}$ & -2.35 & $7.75 \times 10^{-09}$ \\
\hline CSF007_15720 & Hexuronate transporter & -2.38 & $7.15 \times 10^{-28}$ & -2.40 & $1.25 \times 10^{-10}$ \\
\hline CSF007_17650 & Glycerol uptake facilitator protein & -2.39 & $1.55 \times 10^{-28}$ & -2.08 & $5.48 \times 10^{-11}$ \\
\hline CSF007_16005 & Trehalose-6-phosphate hydrolase & -2.46 & $3.37 \times 10^{-14}$ & -3.86 & $3.31 \times 10^{-24}$ \\
\hline CSF007_5810 & $\begin{array}{l}\text { Succinate dehydrogenase } \\
\text { iron-sulfur protein }\end{array}$ & -2.47 & $1.33 \times 10^{-16}$ & -3.06 & $6.67 \times 10^{-15}$ \\
\hline CSF007_13910 & $\begin{array}{l}\text { Ribose/xylose/arabinose/galactoside } \\
\text { ABC-type transport system } \\
\text { periplasmic sugar binding protein }\end{array}$ & -2.48 & $1.26 \times 10^{-19}$ & -3.70 & $1.55 \times 10^{-33}$ \\
\hline CSF007_5800 & $\begin{array}{l}\text { Succinate dehydrogenase } \\
\text { hydrophobic membrane anchor } \\
\text { protein }\end{array}$ & -2.49 & $4.39 \times 10^{-19}$ & -2.64 & $1.15 \times 10^{-10}$ \\
\hline CSF007_17655 & Glycerol kinase & -2.56 & $1.20 \times 10^{-19}$ & -3.31 & $2.81 \times 10^{-15}$ \\
\hline
\end{tabular}


Table 4. Cont.

\begin{tabular}{|c|c|c|c|c|c|}
\hline \multirow{2}{*}{ Gene ID } & \multirow{2}{*}{ Function } & \multicolumn{2}{|c|}{$15 \mathrm{~min}$} & \multicolumn{2}{|c|}{$30 \mathrm{~min}$} \\
\hline & & $\operatorname{logFC}$ & FDR & $\log \mathrm{FC}$ & FDR \\
\hline CSF007_5795 & $\begin{array}{l}\text { Succinate dehydrogenase } \\
\text { cytochrome b-556 subunit }\end{array}$ & -2.64 & $4.76 \times 10^{-26}$ & -2.04 & $9.68 \times 10^{-13}$ \\
\hline CSF007_15715 & hypothetical protein & -2.64 & $2.61 \times 10^{-10}$ & -3.74 & $1.21 \times 10^{-17}$ \\
\hline CSF007_5805 & $\begin{array}{l}\text { Succinate dehydrogenase } \\
\text { flavoprotein subunit }\end{array}$ & -2.65 & $2.01 \times 10^{-22}$ & -3.18 & $3.94 \times 10^{-18}$ \\
\hline CSF007_12450 & $\begin{array}{c}\text { Ascorbate-specific PTS system, } \\
\text { EIIA component }\end{array}$ & -3.07 & $6.74 \times 10^{-23}$ & -3.17 & $6.76 \times 10^{-10}$ \\
\hline CSF007_12455 & $\begin{array}{c}\text { Putative sugar } \\
\text { phosphotransferase component } \\
\text { II B }\end{array}$ & -3.21 & $1.62 \times 10^{-22}$ & -3.52 & $1.76 \times 10^{-09}$ \\
\hline CSF007_5790 & Citrate synthase & -3.23 & $8.51 \times 10^{-22}$ & -3.12 & $8.36 \times 10^{-10}$ \\
\hline CSF007_13905 & hypothetical protein & -3.28 & $2.14 \times 10^{-13}$ & -5.24 & $6.87 \times 10^{-10}$ \\
\hline CSF007_16010 & $\begin{array}{l}\text { PTS system, trehalose-specific IIB } \\
\text { component-PTS system }\end{array}$ & -3.39 & $3.53 \times 10^{-41}$ & -3.85 & $1.29 \times 10^{-27}$ \\
\hline
\end{tabular}

At the mid time point, 30 min p.i., altogether 98 host bacterium genes presented significantly differential pattern of expression. Of the genes, $78 \%$ were significantly downregulated in response to the ongoing YerA41 infection. Further decrease in the expression of host bacterium genes encoding for succinate dehydrogenase complex (CSF007_5805, CSF007_5810, CSF007_5830, CSF007_5800, CSF007_5825, CSF007_5795) and those involved in carbohydrate metabolism and transport of sugars was observed when compared to the $15 \mathrm{~min}$ (early) time point (Table 4). A substantially smaller fraction $(22 \%)$ of host bacterium genes were upregulated when compared to uninfected bacteria. That includes increase in expression of genes encoding cytochrome d ubiquinol oxidase subunits I and II (CSF007_5840 and CSF007_5845) and DNA-binding protein Fis (CSF007_16180)—a prominent factor implicated in bacterial gene regulation. Yet, the strongest overexpression was observed for the cold shock protein CspG (CSF007_10385). Similar to the initial phase of infection, bacteria responded by positive induction of expression of genes encoding the non-specific DNA-binding protein Dps, and catalase.

Interestingly, during the late phase, (60 min p.i.), only 15 host bacterium genes showed significantly different expression level when compared to the uninfected bacteria. All but one (phosphoenolpyruvate synthase, CSF007_9650) showed downregulation of expression. The strongest decrease in expression was observed for genes implicated in the metabolism of fructose, including the fructose-specific phosphocarrier protein HPr, fructose-specific PTS system component and 1-phosphofructokinase (CSF007_11820, CSF007_11810,CSF007_11815). Moreover, during this phase, bacteria downregulated the expression of genes encoding for factors involved in ribonucleotide reduction, such as protein NrdH and reductases of class Ib (CSF007_13980, CSF007_13985, CSF007_13990).

\section{Discussion}

In this study, we show that a transcriptomic approach can be used to obtain the genomic sequence of infectious organisms that cannot be sequenced using traditional DNA based sequencing approaches as they may possess hypermodified deoxyribonucleotides. The major advantage of the method is that it allows us to obtain the sequence of the viral transcriptome and the insight into the phage-host interaction simultaneously during the infection process. Since the phage genomes are characteristically compactly packed with minimal non-coding regions, their transcriptomes constitute the vast majority of genomic sequences, leaving very little of the unresolved genomic sequence.

We performed our RNA-sequencing study on bacterial cells infected at a relatively high MOI $(\mathrm{MOI}=50)$ compared to other phage-host analyses [21,22]. At this MOI value, nearly all the bacterial cells in the culture are infected by the phage; therefore, the pattern of gene expression displayed in this study should reflect the bacterial response to lytic phage infection. One interesting phenomenon observed in this study was that the number of differentially expressed bacterial host genes decreased 
throughout the course of infection. We believe that it is caused by some degree of degradation of host transcripts, in combination with differences in ratio between the infected and uninfected bacteria in later phases of infection. In this situation, the degraded RNA transcripts from the infected cells would be lost.

Based upon active gene expression during infection, the YerA41 genome contains $>201$ putative genes; however, of these, only 60 could be assigned a predictive function. The remaining gene products exibited very limited amino acid sequence similarity to other proteins deposited in the databases, further illustrating the novelty of the YerA41 bacteriophage. Among the known gene products, there were several DNAP, RNAP $\beta$ - and $\beta$ '-subunits, topoisomerases, DNA ligase, helicases, as well as endoand exonucleases. The functional analysis of these genes also revealed the presence of a putative endolysin (g49). Due to the ability to lyse bacterial cell walls, endolysins are considered to be of special interest as potential novel antimicrobials $[23,24]$. A very interesting group of genes were identified from scaffold 2, where the gene g064-g070 products showed similarities sugar biosynthesis related enzymes, suggesting that they might play a role in biosynthesis of sugar-modified nucleotides.

The obtained genomic sequence indicates that YerA41 is a member of a novel, previously unidentified, group of bacteriophages. At the nucleotide level it shares no significant similarity with genomic sequences of any known organisms deposited in the databases. Conversely, the in silico analysis revealed the presence of multiple unique proteins that are predicted to be involved in nucleic acid processing and metabolism. Taking this into consideration, it is logical that it is equipped with its own machinery for transcription and amplification of the genetic information. At the moment, the exact nature of the nucleotide modification present in the genome of YerA41 is still unknown, but the research tackling this question is ongoing.

Supplementary Materials: The following are available online at http://www.mdpi.com/1999-4915/12/6/620/s1, Figure S1. One-step growth curve of bacteriophage YerA41. Table S1. Bacterial strains used in this study; Table S2. List of putative protein coding genes identified in YerA41 sequence scaffolds. Table S3. Transcriptional response in YerA41 infected Y. ruckeri cells. The lists of genes differentially expressed at 15, 30 and 60 min p.i.

Author Contributions: Conceptualization, M.S., K.L., and M.I.P.; methodology, M.I.P., M.V.G.-R.V., S.K., K.L., D.S., and A.N.; software, K.L., M.S., and D.S.; validation, M.I.P. and K.L.; resources, M.S.; writing-original draft preparation, K.L. and M.S.; writing—review and editing, M.S., K.L., M.I.P., M.V.G.-R.V., S.K., D.S., and A.N.; funding acquisition, M.S. All authors have read and agreed to the published version of the manuscript.

Funding: This study has been carried out in M.S. lab ever since we received the phage YerA41 from late Hans-Wolfgang Ackermann in 2003. Throughout the years the work has been supported in bits and pieces by the Academy of Finland grants (project numbers 40932, 45820, 50441, 104361, 114075, 201358, 203602, 288701). Open access funding provided by University of Helsinki.

Acknowledgments: We thank Patrycja Pluta for help in determination of the host range and the one step growth curve for YerA41.

Conflicts of Interest: The authors declare no conflict of interest.

\section{References}

1. Stevenson, R.M.W.; Airdrie, D.W. Isolation of Yersinia ruckeri bacteriophages. Appl. Environ. Microbiol. 1984, 47, 1201-1205. [CrossRef] [PubMed]

2. Ackermann, H.-W.; DuBow, M.S.; Gershman, M.; Karska-Wysocki, B.; Kasatiya, S.S.; Loessner, M.J.; Mamet-Bratley, M.D.; Regué, M. Taxonomic changes in tailed phages of enterobacteria. Arch. Virol. 1997, 142, 1381-1390. [CrossRef] [PubMed]

3. Gommers-Ampt, J.H.; Borst, P. Hypermodified bases in DNA. Faseb J. 1995, 9, 1034-1042. [CrossRef] [PubMed]

4. Weigele, P.; Raleigh, E.A. Biosynthesis and Function of Modified Bases in Bacteria and Their Viruses. Chem. Rev. 2016, 116, 12655-12687. [CrossRef] [PubMed]

5. Warren, R.A. Modified bases in bacteriophage DNAs. Ann. Rev. Microbiol. 1980, 34, 137-158. [CrossRef] 
6. Song, H.K.; Sohn, S.H.; Suh, S.W. Crystal structure of deoxycytidylate hydroxymethylase from bacteriophage T4, a component of the deoxyribonucleoside triphosphate-synthesizing complex. Embo J. 1999, 18, 1104-1113. [CrossRef]

7. Vrielink, A.; Ruger, W.; Driessen, H.P.; Freemont, P.S. Crystal structure of the DNA modifying enzyme beta-glucosyltransferase in the presence and absence of the substrate uridine diphosphoglucose. Embo J. 1994, 13, 3413-3422. [CrossRef]

8. Kiljunen, S.; Hakala, K.; Pinta, E.; Huttunen, S.; Pluta, P.; Gador, A.; Lönnberg, H.; Skurnik, M. Yersiniophage fR1-37 is a tailed bacteriophage having a $270 \mathrm{~kb}$ DNA genome with thymidine replaced by deoxyuridine. Microbiology 2005, 151, 4093-4102. [CrossRef]

9. Sambrook, J.; Russell, D.W. Molecular Cloning: A Laboratory Manual, the Third Edition, 2nd ed.; Cold Spring Harbor Laboratory: Cold Spring Harbor, NY, USA, 2001.

10. Ellis, E.L.; Delbruck, M. The Growth of Bacteriophage. J. Gen. Physiol. 1939, 22, 365-384. [CrossRef]

11. Pajunen, M.; Kiljunen, S.; Skurnik, M. Bacteriophage fYeO3-12, specific for Yersinia enterocolitica serotype O:3, is related to coliphages T3 and T7. J. Bacteriol. 2000, 182, 5114-5120. [CrossRef]

12. Langmead, B.; Salzberg, S.L. Fast gapped-read alignment with Bowtie 2. Nat. Methods 2012, 9, 357-359. [CrossRef] [PubMed]

13. Zerbino, D.R.; Birney, E. Velvet: Algorithms for de novo short read assembly using de Bruijn graphs. Genome Res. 2008, 18, 821-829. [CrossRef] [PubMed]

14. Bankevich, A.; Nurk, S.; Antipov, D.; Gurevich, A.A.; Dvorkin, M.; Kulikov, A.S.; Lesin, V.M.; Nikolenko, S.I.; Pham, S.; Prjibelski, A.D.; et al. SPAdes: A new genome assembly algorithm and its applications to single-cell sequencing. J. Comput. Biol. 2012, 19, 455-477. [CrossRef]

15. Rutherford, K.; Parkhill, J.; Crook, J.; Horsnell, T.; Rice, P.; Rajandream, M.A.; Barrell, B. Artemis: Sequence visualization and annotation. Bioinformatics 2000, 16, 944-945. [CrossRef] [PubMed]

16. Anders, S.; Pyl, P.T.; Huber, W. HTSeq-A Python framework to work with high-throughput sequencing data. Bioinformatics 2015, 31, 166-169. [CrossRef] [PubMed]

17. Robinson, M.D.; McCarthy, D.J.; Smyth, G.K. edgeR: A Bioconductor package for differential expression analysis of digital gene expression data. Bioinformatics 2010, 26, 139-140. [CrossRef]

18. Varjosalo, M.; Keskitalo, S.; Van Drogen, A.; Nurkkala, H.; Vichalkovski, A.; Aebersold, R.; Gstaiger, M. The protein interaction landscape of the human CMGC kinase group. Cell Rep. 2013, 3, 1306-1320. [CrossRef]

19. Skurnik, M.; Bengoechea, J.A. The biosynthesis and biological role of lipopolysaccharide O-antigens of pathogenic Yersiniae. Carbohydr. Res. 2003, 338, 2521-2529. [CrossRef]

20. Aziz, R.K.; Bartels, D.; Best, A.A.; DeJongh, M.; Disz, T.; Edwards, R.A.; Formsma, K.; Gerdes, S.; Glass, E.M.; Kubal, M.; et al. The RAST Server: Rapid annotations using subsystems technology. BMC Genom. 2008, 9, 75. [CrossRef]

21. Blasdel, B.G.; Chevallereau, A.; Monot, M.; Lavigne, R.; Debarbieux, L. Comparative transcriptomics analyses reveal the conservation of an ancestral infectious strategy in two bacteriophage genera. ISME J. 2017, 11, 1988-1996. [CrossRef]

22. Sacher, J.C.; Flint, A.; Butcher, J.; Blasdel, B.; Reynolds, H.M.; Lavigne, R.; Stintzi, A.; Szymanski, C.M. Transcriptomic Analysis of the Campylobacter jejuni Response to T4-Like Phage NCTC 12673 Infection. Viruses 2018, 10, 332. [CrossRef] [PubMed]

23. Nelson, D.C.; Schmelcher, M.; Rodriguez-Rubio, L.; Klumpp, J.; Pritchard, D.G.; Dong, S.L.; Donovan, D.M. Endolysins as Antimicrobials. Adv. Virus Res. Vol 83 Bacteriophages Pt B 2012, 83, 299-365. [CrossRef]

24. Schmelcher, M.; Donovan, D.M.; Loessner, M.J. Bacteriophage endolysins as novel antimicrobials. Future Microbiol. 2012, 7, 1147-1171. [CrossRef] [PubMed]

(C) 2020 by the authors. Licensee MDPI, Basel, Switzerland. This article is an open access article distributed under the terms and conditions of the Creative Commons Attribution (CC BY) license (http://creativecommons.org/licenses/by/4.0/). 